\title{
Sustained Axon-Glial Signaling Induces Schwann Cell Hyperproliferation, Remak Bundle Myelination, and Tumorigenesis
}

\author{
Jose A. Gomez-Sanchez, ${ }^{1,3}$ Mikel Lopez de Armentia, ${ }^{2}$ Rafael Lujan, ${ }^{4}$ Nicoletta Kessaris, ${ }^{5}$ William D. Richardson, ${ }^{5}$ \\ and Hugo Cabedo ${ }^{1,3}$ \\ ${ }^{1}$ Biology of Myelin Diseases Laboratory and ${ }^{2}$ Synaptic Plasticity and Regulation of Gene Expression Laboratory, Instituto de Neurociencias de Alicante, \\ Universitat Miguel Hernandez-Consejo Superior de Investigaciones Científicas, 03550 Sant Joan, Alicante, Spain, ${ }^{3}$ Unidad de Investigación del Hospital de \\ Sant Joan, 03550 Sant Joan, Alicante, Spain, ${ }^{4}$ Centro Regional de Investigaciones Biomédicas, Universidad de Castilla-La Mancha, 02006 Albacete, Spain, \\ and ${ }^{5}$ Wolfson Institute for Biomedical Research, University College London, WC1E 6BT London, United Kingdom
}

\begin{abstract}
Type III neuregulins exposed on axon surfaces control myelination of the peripheral nervous system. It has been shown, for example, that threshold levels of type III $\beta$ la neuregulin dictate not only the myelination fate of axons but also myelin thickness. Here we show that another neuregulin isoform, type III- $\beta 3$, plays a distinct role in myelination. Neuronal overexpression of this isoform in mice stimulates Schwann cell proliferation and dramatically enlarges peripheral nerves and ganglia-which come to resemble plexiform neurofibromas- but have no effect on myelin thickness. The nerves display other neurofibroma-like properties, such as abundant collagen fibrils and abundant dissociated Schwann cells that in some cases produce big tumors. Moreover, the organization of Remak bundles is dramatically altered; the small-caliber axons of each bundle are no longer segregated from one another within the cytoplasm of a nonmyelinating Schwann cell but instead are close packed and the whole bundle wrapped as a single unit, frequently by a compact myelin sheath. Because Schwann cell hyperproliferation and Remak bundle degeneration are early hallmarks of type I neurofibromatosis, we suggest that sustained activation of the neuregulin pathway in Remak bundles can contribute to neurofibroma development.
\end{abstract}

\section{Introduction}

Compact myelin is a vertebrate-specific adaptation that dramatically increases nerve conduction velocity. The formation of myelin by Schwann cells in the peripheral nervous system (PNS) is primarily dependent on axon-derived signals (for review, see Sherman and Brophy, 2005). Recently, it was shown that Neuregulin 1 (NRG1) gene products expressed in PNS neurons are pivotal for the survival and proliferation of Schwann cell lineage (Levi et al., 1995; Morrissey et al., 1995; Wolpowitz et al., 2000). It was also elegantly demonstrated that later, axon surface-exposed neuregulins provide instructive signals for the myelination of peripheral neurons (Michailov et al., 2004; Sherman and Brophy, 2005; Taveggia et al., 2005).

Neuregulins are a group of cell-cell signaling molecules that act as ligands of ErbB receptor tyrosine kinases. NRG1 is a highly

\footnotetext{
Received April 11, 2009; revised July 20, 2009; accepted July 28, 2009.

This work was supported by the Spanish Ministry of Health "Instituto de Salud Carlos III" Grant PI05/0535 and "Conselleria de Salut de la Generalitat Valenciana" Grant AP-002/06 (H.C.). This work was also partially supported by Spanish Ministerio de Ciencia e Innovación Grant CSD2007-00023. J.A.G. was supported by a predoctoral fellowship from the Spanish Ministry of Health (Instituto de Salud Carlos III, PI05/0535). We thank A. Barco for kindly hosting the electrophysiological experiments. We thank Pedro Morenilla-Ayala, Consuelo Martinez-Moratalla, Ulla Dennehy, and Matthew Grist for technical assistance.

Correspondence should be addressed to Hugo Cabedo, Instituto de Neurociencias de Alicante Universitat Miguel Hernández-Consejo Superior de Investigaciones Cientificas, Avda Santiago Ramon y Cajal sn, 03550 Sant Joan, Alicante, Spain. E-mail: hugo.cabedo@umh.es.

D0I:10.1523/JNEUROSCI.1753-09.2009

Copyright $\odot 2009$ Society for Neuroscience $\quad$ 0270-6474/09/2911304-12\$15.00/0
}

spliced gene with $>15$ isoforms, each containing an epidermal growth factor-like domain that is essential for receptor binding and activation. According to the structure of their N-terminal domains, three main types of splicing products (type I-III) with specific biological roles have been described (Falls, 2003). It has been shown that only type III isoforms (characterized by a cysteine-rich domain) are involved in the control of PNS myelination (Michailov et al., 2004; Taveggia et al., 2005). Type III isoforms control not only myelination but also the ensheathment of small-diameter axons and their segregation by the cytoplasm of nonmyelinating Schwann cells (nmSC) in so-called Remak bundles (Taveggia et al., 2005).

Two different neuregulin type III isoforms have been so far described, type III- $\beta 1 \mathrm{a}$ and type III- $\beta 3$ (Ho et al., 1995 ; Schroering and Carey, 1998; Falls, 2003). Gain-of-function studies on the role the type III isoforms in myelination have been exclusively conducted with the type III- $\beta$ 1a splicing form. However, the type III- $\beta 3$ isoform (also known as SMDF, for sensory and motorneuron derived factor) is also highly expressed in PNS neurons, suggesting that it could have a role in myelin development. To determine the role of this isoform in myelination, we have generated transgenic mice that overexpress human SMDF (hSMDF) under the control of the rat neuron-specific enolase (NSE) promoter. We show that, although SMDF overexpression has no major effects on myelin thickness around individual largediameter axons, it has dramatic effects on the structure of the Remak bundles. The small-caliber axons in these bundles are not 
segregated one from another within the Schwann cell cytoplasm as they normally are but remain as a close-packed bundle that is ensheathed as a single entity. Strikingly, the ensheathing Schwann cells in mutant Remak bundles elaborate a compact myelin sheath around the exterior of the axon bundle. We also show that overexpression of SMDF provokes a dramatic proliferation of nmSC, suggesting that neuregulin is an in vivo mitogenic signal for these cells. Akin to type I neurofibromatosis (Ling et al., 2005; Zheng et al., 2008), mutant nerves show increased deposits of collagen fibrils in the extracellular space and, in some cases, develop big tumors, suggesting that neuregulin overexpression in the small-sized axons of Remak bundles could be involved in the development of neurofibroma and other peripheral nerve tumors.

\section{Materials and Methods}

Generation of NSE-hSMDF transgenic mice. All the procedures involving animals were performed following European Union and United Kingdom guidelines. The cDNA encoding for the human SMDF was directionally cloned in the XbaI, NotI restriction sites of the NSE-mouse platelet-derived growth factor alfa chain plasmid (Fruttiger et al., 1996). The sequence of the construct was verified by DNA sequencing. The NSE promoter, hSMDF cDNA, and simian virus 40 poly(A) were excised with EcoRI and injected into fertilized C57BL/6 hybrid mouse oocytes. These were transferred into pseudopregnant female mice. Two founders, able to transmit and express the transgene, were used to establish two transgenic mouse lines, NSE- hSMDF\#1 and NSE-hSMDF\#2. Mice were genotyped by PCR using human-specific SMDF primers (sense, 5'_GAGTCTGCAGTCCTCGACCT; antisense, 5'_GATGGGGACAATGCAGATT).

$m R N A$ detection and quantification by reverse transcription and quantitative PCR. To detect and quantify gene expression, animals were killed, the sciatic nerve was dissected, and total RNA was isolated using Purelink Micro-To-Midi kit according to the instructions of the manufacturer (Invitrogen). Genomic DNA was removed by incubation with RNasefree DNase I (Fermentas), and RNA was primed with random hexamers and retrotranscribed to cDNA with SuperScript II Reverse transcriptase (Invitrogen). Control reactions were performed omitting retrotranscriptase. The same primers used for genotyping were used for reverse transcription (RT)-PCR. To control the quality of the cDNA, housekeeping mRNA (SREBP2) was amplified (sense, 5'_AAGTCTGGCGTTCTGAGGAA; antisense, 5'_CCAGGAAGGTGAGGACACAT). Quantitative real-time PCR (qPCR) was performed using the Applied Biosystems 7500 Real Time PCR System and Platinum SYBR_Green qPCR SupermixUDG (Invitrogen). To avoid genomic amplification, PCR primers were designed to fall into separate exons flanking a large intron. Reactions were performed in duplicates of three different dilutions, and threshold cycle values were normalized to the housekeeping gene $18 \mathrm{~S}$. The specificity of the products was determined by melting curve analysis and gel electrophoresis. The ratio of the relative expression for each gene to $18 \mathrm{~S}$ was calculated by using the $2^{\Delta \mathrm{CT}}$ formula (Table 1 ).

To quantify the amount of mRNA for SMDF in peripheral neurons, qPCR was performed with primers able to amplify both the human and mouse SMDF (SMDF human/mouse sense, 5'_GCC CAA ATG AGT TTA CTG GTG; SMDF human/mouse antisense, 5'_GCT CCT ATT CAG GCA GAG ACA G). Results were normalized to 18 .

Calculating the number of integrated copies. The number of transgene copies was evaluated as described previously (Mitrecic et al., 2005; Haurogne et al., 2007). Briefly, genomic DNA was extracted from tail biopsies using standard protocols, and DNA concentrations were determined with an UV spectrophotometer (Nanodrop). DNA stock solutions at $50 \mathrm{ng} / \mu \mathrm{l}$ were prepared, and the actual concentration was reevaluated (mean of five measurements). According to this result, two dilutions were prepared $(6.25$ and $3.13 \mathrm{ng} / \mu \mathrm{l}$ of genomic DNA). For qPCR reaction, we always used a $2 \mu \mathrm{l}$ of sample of each dilution. The primer sequences used for the transgene were as follows: sense, $5^{\prime}$ _GAGTCTGCAGTCCTCGACCT; antisense, 5'_GATGGGGACAATGCAGATT. A fragment of
Table 1. Primers used in this study to amplify the myelin related genes

\begin{tabular}{|c|c|c|c|}
\hline Primer & GenBank accession number & & Sequence $\left(5^{\prime} \rightarrow 3^{\prime}\right)$ \\
\hline \multirow[t]{2}{*}{ MBP } & NM_0100777 & Sense & ATCCAAGTACCTGGCCACAG \\
\hline & & Antisense & CCTGTCACCGCTAAAGAAGC \\
\hline \multirow[t]{2}{*}{ P0 } & NM_008623 & Sense & ACCAGACATAGTGGGCAAGACCTC \\
\hline & & Antisense & AAGAGCAACAGCAGCAACAGCACC \\
\hline \multirow[t]{2}{*}{ CNPase } & NM_009923 & Sense & TGCTGCACTGTACAACCAAATTC \\
\hline & & Antisense & GTGTCACAAAGAGAGCAGAGATGG \\
\hline \multirow[t]{2}{*}{ HMGCR } & NM_008255 & Sense & TGGATCGAAGGACGAGGAAAG \\
\hline & & Antisense & GAATTACGTCAACCATAGCTTCCG \\
\hline \multirow[t]{2}{*}{185} & NR_003278 & Sense & CGGCTACCACATCCAAGGAA \\
\hline & & Antisense & GCTGGAATTACCGCGGCT \\
\hline
\end{tabular}

the same size ( $\sim 250 \mathrm{bp}$ ) was also amplified from the mGJA5 housekeeping gene (GenBank accession number NM_008121; primer sense, 5'_GCCTATGAGTACCCAGTAGCCG; antisense, 5'_CGTGGGCCTCGAAACATAAC). The number of transgene copies was calculated using the $2^{\Delta \mathrm{CT}}$ formula.

In situ hybridization. Antisense RNA probes for in situ hybridization were prepared from human SMDF cDNA cloned in pcDNA3 (Cabedo et al., 2002). In situ hybridization was performed as described previously (Fruttiger et al., 1999).

Immunoblotting and lectin binding. Tissues were homogenized at $4^{\circ} \mathrm{C}$ in radioimmunoprecipitation assay buffer (1\% Nonidet P- $40,1 \%$ sodium deoxycholate, $0.1 \%$ SDS, and $5 \mathrm{~mm}$ EGTA) containing protease inhibitors (Complete tablets; Roche) and phosphatase inhibitors (50 mM sodium fluoride and $0.2 \mathrm{~mm}$ sodium vanadate). Protein concentrations were determined by the BCA method (Pierce). For Western blotting, 6-15 $\mu \mathrm{g}$ of total protein was subjected to SDS-PAGE and blotted onto Protran nitrocellulose membrane (Whatman Schleicher and Schuell). Membranes were incubated overnight at $4^{\circ} \mathrm{C}$ with the indicated specific primary antibody, washed and incubated with secondary antibodies, and developed with ECLplus (GE Healthcare). The primary antibodies used were as follows: mouse monoclonal anti-glial fibrillary acidic protein (GFAP) (1:1000; Millipore Bioscience Research Reagents) and anti- $\beta$-actin antibodies (1:2000; Sigma); rabbit polyclonal anti-mitogen-activated protein kinase (MAPK), anti-phospho-MAPK p44-42, anti-AKT, and antiphospho-AKT (Ser473) antibodies (1:1000; Cell Signaling Technology); rabbit polyclonal anti-heregulin $\beta 3$ and anti-ErbB3 antibodies (1:500; Santa Cruz Biotechnologies); and anti-phospho-Histone H3 (pSer10) (1:200; Sigma) and anti-Krox-20 (Egr2) rabbit polyclonal antibodies (1: 100 ; Covance). Goat polyclonal antibodies were anti-MBP (clone D-18) (1:500; Santa Cruz Biotechnologies) and anti-apolipoprotein E (ApoE) (1:500; Millipore Bioscience Research Reagents). The secondary antibodies were conjugated with horseradish peroxidase (1:2000; Sigma). For lectin binding, tissues were lysed with $10 \mathrm{~mm}$ Tris- $\mathrm{HCl}$, $\mathrm{pH} 7.5,100 \mathrm{~mm} \mathrm{NaCl}, 0.4 \%$ sodium deoxycholate, $0.3 \%$ SDS, and $1 \%$ Nonidet P-40, and extracts were incubated with $80 \mu \mathrm{l}$ of wheat germ agglutinin-agarose lectin, extensively washed with lysis buffer, and analyzed by immunoblotting.

Immunohistochemistry. Mice were killed, and sciatic nerves were dissected, fixed overnight in $4 \%$ paraformaldehyde, and cryoprotected by sequential immersion in 5, 15, and $30 \%$ sucrose in PBS at $4^{\circ} \mathrm{C}$. Fixed nerves were embedded in O.C.T. (TissueTek; Sakura) and frozen on dry ice. Longitudinal or transversal nerve sections were blocked for $2 \mathrm{~h}$ in $5 \%$ goat serum and $0.3 \%$ Triton X-100 in PBS. Primary antibodies (antiS100 at 1:400 and anti-GFAP at 1:500) were diluted in $1 \%$ goat serum and $0.3 \%$ Triton X-100 in PBS and incubated at $4^{\circ} \mathrm{C}$. Sections were then washed with PBS, and detection was performed using the appropriate fluorescent secondary antibodies (AlexaFluor 594 anti-mouse, AlexaFluor 488 anti-rabbit, 1:700; Invitrogen) for $1 \mathrm{~h}$. Nuclei were counterstained with bisbenzimide (Hoechst nuclear stain) in PBS. Samples were mounted in Fluoromount G (Southern Biotechnology Associates). Anti-Krox-20 immunohistochemistry was performed as described by Le et al. (2005).

Cell proliferation analysis. Cell proliferation was measured by bromodeoxyuridine (BrdU) (Sigma) incorporation. Transgenic mice and littermates [postnatal day 5 (P5) or P14] were administered four doses of 
BrdU (50 mg/kg in PBS) intraperitoneally at $2 \mathrm{~h}$ intervals. Sciatic nerves were subsequently dissected, and cells were disaggregated and plated on coverslips. After cell attachment $(8-12 \mathrm{~h})$, cells were processed for BrdU immunostaining. Briefly, cells were fixed in $4 \%$ paraformaldehyde for 30 min, washed in PBS, treated with $2 \mathrm{~N} \mathrm{HCl}$ for $30 \mathrm{~min}$ at $37^{\circ} \mathrm{C}$, washed in borate buffer, $\mathrm{pH} 8.3$, and PBS, and blocked in PBS containing $0.5 \%$ Triton X-100 and 5\% goat serum. Processed cells were incubated with a mouse anti-BrdU (1:500; Sigma) and a rabbit anti-S100 (1:400; Sigma) antibody for $2 \mathrm{~h}$ at $37^{\circ} \mathrm{C}$ and then washed with PBS. Detection was performed using fluorescent secondary antibodies (AlexaFluor 546 antimouse and AlexaFluor 488 anti-rabbit, 1:1000). Samples were mounted in Fluoromount G (Southern Biotechnology Associates). To calculate the mitotic index, anti-phospho-Histone H3 (1:200) immunohistochemistry was used.

Toluidine blue staining and transmission electron microscopy. Mice were profoundly anesthetized by intraperitoneal injection of $40 \mathrm{mg} / \mathrm{kg}$ ketamine and $30 \mathrm{mg} / \mathrm{kg}$ xylazine and then intracardially perfused with $2 \%$ paraformaldehyde, $2.5 \%$ glutaraldehyde, and $0.1 \mathrm{~m}$ phosphate buffer, $\mathrm{pH}$ 7.4. Tissues were dissected and immersed in the same fixative solution at $4^{\circ} \mathrm{C}$ overnight, washed in phosphate buffer, postfixed in $1 \%$ osmium tetroxide, dehydrated in graded ethanol series, and embedded in epoxy resin (Durcupan). Semithin sections were cut with a glass knife at 1-3 $\mu \mathrm{m}$ and stained with toluidine blue. Images were obtained with a $63 \times$ objective in an inverted microscope (Nikon) and digitalized with MetaMorph 7.1 software (Molecular Devices). For electron microscopy, ultrathin sections $(70-90 \mathrm{~nm}$ ) were cut on an ultramicrotome (Reichert Ultracut E; Leica) and collected on 200-mesh nickel grids. Staining was performed on drops of $1 \%$ aqueous uranyl acetate, followed by Reynolds's lead citrate. Ultrastructural analyses were performed in a Jeol1010 electron microscope. $g$-Ratio and axon perimeter were calculated using NIH ImageJ. Electron microscopy images were used for calculating the $g$-ratio. Axon perimeter measurements were performed on images taken on a light microscope. At least 100 randomly selected axons were analyzed per animal. Three or more animals were used per genotype.

Gomori's staining. Sciatic nerves were sectioned longitudinally $(10 \mu \mathrm{m}$ thickness) and fixed in 4\% paraformaldehyde for $15 \mathrm{~min}$, washed in water, stained in Gomori's Trichrome Stain LG for $5 \mathrm{~min}$, and washed again with $0.5 \%$ acetic acid for $1 \mathrm{~min}$. Then, slides were sequentially dehydrated in 70, 95, and 100\% alcohol series, cleared in xylene, and mounted with Permount (Thermo Fisher Scientific). Images were obtained with AxioCamHRC (Carl Zeiss) in DM5000R microscopes (Leica) under a $20 \times$ objective.

Electrophysiology. Mice were anesthetized by intraperitoneal injection of $40 \mathrm{mg} / \mathrm{kg}$ ketamine and $30 \mathrm{mg} / \mathrm{kg}$ xylazine and then perfused with oxygenated ( $95 \% \mathrm{O}_{2} / 5 \% \mathrm{CO}_{2}$ ) saline containing the following (in $\mathrm{mM}$ ): $133 \mathrm{NaCl}, 16.3 \mathrm{NaHCO}_{3}, 1.3 \mathrm{NaH}_{2} \mathrm{PO}_{4}, 3.6 \mathrm{KCl}, 1.2 \mathrm{MgSO}_{4}, 1.2 \mathrm{CaCl}_{2}$, and 7.8 glucose. Sciatic nerves were dissected and placed in a recording chamber superfused with the same solution. Electrical stimuli were applied using a suction electrode at one end of the nerve, and compound action potentials were recorded with a pipette filled with $1 \mathrm{M} \mathrm{NaCl}(5$ $\mathrm{M} \Omega$ ) at the other end. Signals were recorded using a MultiClamp 700B amplifier (Molecular Devices), filtered at $10 \mathrm{kHz}$ and digitized at $20 \mathrm{kHz}$ (Digidata1320A; Molecular Devices), and analyzed with AxoGraph X 1.0 (AxoGraph Scientific). To increase the signal-to-noise ratio, 40 sweeps were averaged.

\section{Results}

\section{Neuronal overexpression of type III- $\beta 3$ NRG1: NSE-SMDF transgenic mice}

Although it is well established that overexpression of the type III- $\beta 1$ a isoform of Neuregulin 1 increases myelin thickness in the PNS, the effects of type III- $\beta 3$ isoform overexpression have not been yet determined. To explore this point, we produced transgenic mice expressing the human type III- $\beta 3$ neuregulin in neurons, under transcriptional control of a $1.8 \mathrm{~kb}$ NSE promoter fragment from rat (Fig. 1a), which has been used previously to target transgene expression to postnatal neurons (Forss-Petter et al., 1990; Fruttiger et al., 1996; Calver et al., 1998). Two founder

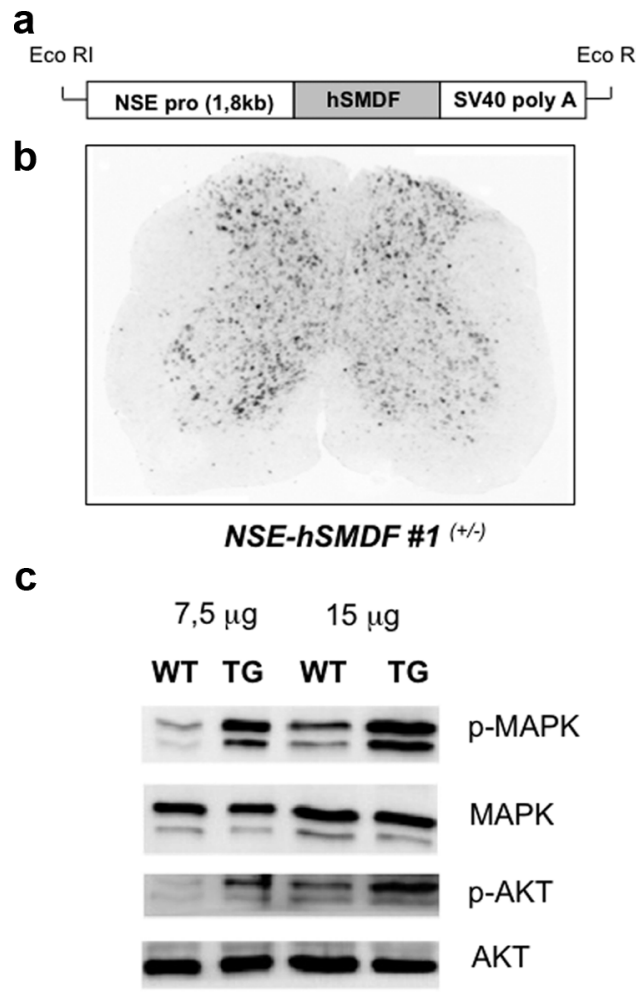

Figure 1. Strategy to overexpress type III- $\beta 3$ neuregulin 1 in neurons. $\boldsymbol{a}$, To drive the expression of type III- $\beta 3$ neuregulin into CNS and PNS neurons, the cDNA encoding for the human SMDF was cloned under the $1.8 \mathrm{~kb}$ promoter of the rat NSE and microinjected into fertilized mouse oocytes (see Material and Methods). $\boldsymbol{b}$, In situ hybridization with a human hSMDF probe shows that the transgene is expressed in neurons (gray matter) but not in glial cells (white matter) in the NSE-SMDF\#1 ${ }^{+/-}$mice. c, The overexpression of hSMDF induces the sustained activation of the MAPK and PI3K pathways in the PNS. Protein extracts from P20 sciatic nerves were submitted to SDS-PAGE and blotted with anti-phospho-MAPK kinase or anti-phosphoAkt-specific antibodies. The incubation with anti-MAPK and anti-Akt (total protein) illustrates that the increase in phospho-immunoreactivity was not caused by changes in the amount of protein. WT, Wild type; TG, transgenic.

lines (\#1 and \#2) were derived that contained $\sim 24$ and $\sim 7$ transgene copies per genome, respectively (supplemental Fig. S1, available at www.jneurosci.org as supplemental material). Both lines were fertile and developed no obvious phenotype during the first few months of life. In situ hybridization with a probe specific for $h S M D F$ showed that both lines expressed the NSE-hSMDF transgene in cells of the spinal cord gray matter but not white matter, consistent with neuron-specific expression (Fig. 1b) (supplemental Fig. S2, available at www.jneurosci.org as supplemental material). Unless otherwise stated, the work described from here on concerns transgenic line \#1. To determine whether mRNA encoded by the transgene is translated to protein, SMDF (and other glycosylated proteins) from adult NSE- $h S M D F$ brain and sciatic nerve homogenates were concentrated by lectin binding (Cabedo et al., 2004) and immunoblotted with an antineuregulin $\beta 3$-specific antibody (see Material and Methods). As shown in supplemental Figure S3 (available at www.jneurosci.org as supplemental material), SMDF immunoreactivity was noticeably increased in the nervous tissue of the NSE-hSMDF mice. To further define the expression pattern of the transgene we performed RT-PCR experiments with primers designed to amplify $h S M D F$ but not endogenous mouse SMDF. As is shown in supplemental Figure S4 (available at www.jneurosci.org as supplemental material), transgene-derived mRNA is found in neural tissues (forebrain, cerebellum, spinal cord, trigeminal, and dorsal 
a

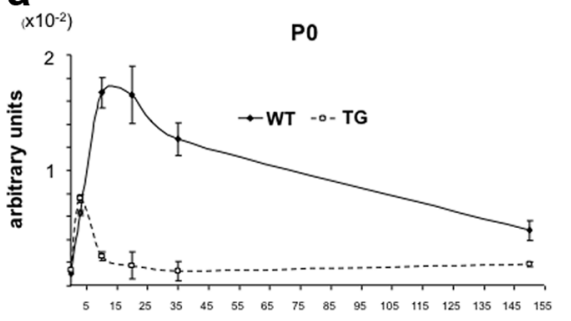

age (days)

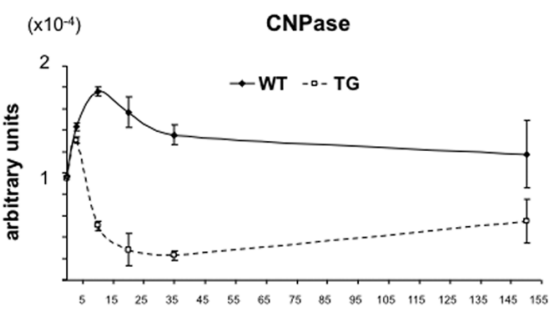

age (days)

b

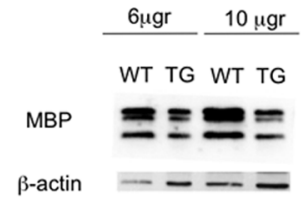

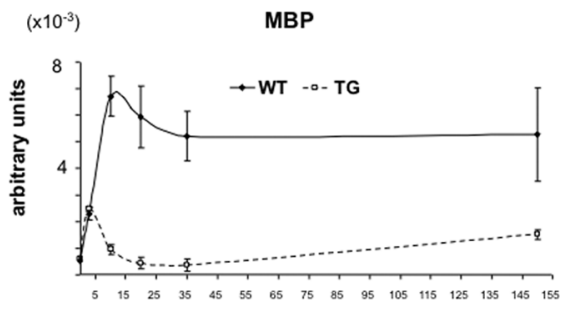

age (days)

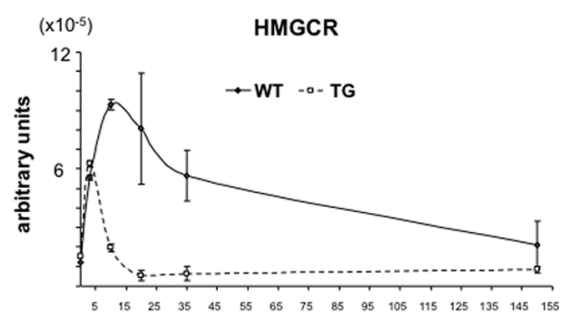

age (days)

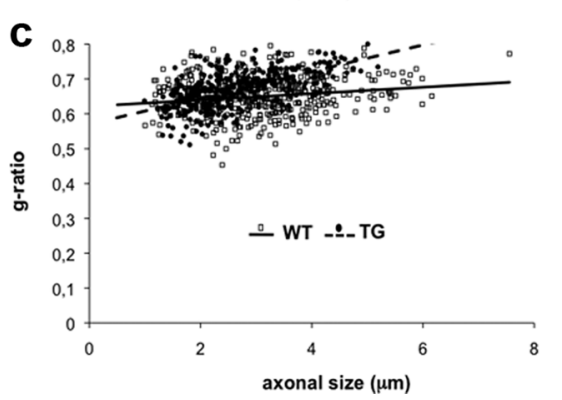

Figure 2. Overexpression of hSMDF induces a dramatic decrease in the myelin protein expression, which reflects no real myelination deficit. $\boldsymbol{a}$, The mRNA for $\mathrm{PO}, \mathrm{MBP}$, CNPase, and $\mathrm{HMGCOA}$ reductase is dramatically downregulated in the sciatic nerves of the NSE-hSMDF\#1 ${ }^{+/-}$mice. CDNA from P0, P3, P10, P20, P35, and P150 was analyzed for the expression of these genes by qPCR. mRNA levels are expressed in arbitrary units after normalization to a housekeeping gene (18S). $\boldsymbol{b}$, The drop in mRNA is reflected in a decrease in the steady-state levels of myelin proteins as shown by the anti-MBP Western blot of protein extracts of P20 NSE-hSMDF\#1 $1^{+/-}$sciatic nerves and wild-type littermates. c, Myelin thickness is not altered in the mutant nerves. Myelin thickness was estimated by determining the $g$-ratio in EM images obtained from mutant P20 mice and wild-type littermates (see Material and Methods). $g$-Ratio was plotted against axon size. Four animals per genotype were used. Except for a slight increase for larger axons, no significant changes in $g$-ratios could be observed. Data are given as mean \pm SE. WT, Wild type; TG, transgenic.

the sustained activation of two key signaling pathways for the proliferation and differentiation of Schwann cells.

Effect of SMDF overexpression on PNS development and myelination

We investigated the expression of myelinrelated genes in the sciatic nerves during postnatal development of the NSE-hSMDF mice. mRNA encoding $2^{\prime}, 3^{\prime}$-cyclic nucleotide phosphodiesterase (CNP), the myelin lipid biosynthetic enzyme hydroxy-methylglutaryl coenzyme A (HMGCoA) reductase, and myelin structural proteins protein zero (P0) and myelin basic protein (MBP) were quantified by $\mathrm{qPCR}$ in total RNA from P0, P3, P10, P20, P35, and P150 NSE- $h S M D F^{+/-}$mice and wild-type littermates (see Material and Methods). Gene expression levels were normalized against $18 \mathrm{~S}$ rRNA. As is shown in Figure $2 a$, each of the selected Schwann cell mRNAs was dramatically downregulated in NSE-hSMDF mice. The reduction in $M B P$ transcripts was accompanied by a reduction of $53 \pm 1.1 \%$ in MBP protein $(n=4)$, revealed by immunoblotting P20 sciatic nerve extracts (Fig. $2 b$ ). The reduction in myelin-related mRNAs was also observed, to a lesser extent, in the NSEhSMDF transgenic line \#2 ( 7 integrated copies rather than $\sim 24$ ) (supplemental Fig. S5, available at www.jneurosci.org as supplemental material), suggesting that the reduction in myelin gene expression is the consequence of neuregulin overexpression and not transgene positional effects. Myelin protein expression has been widely used as a surrogate marker of myelination; however, there are situations in which myelin protein expression does not root ganglia) but not in non-neural tissues (heart, liver, and kidney). Using qPCR, we estimated that the expression of mRNA for SMDF in the peripheral neurons of line \#1 transgenic animals is increased by almost sevenfold $(6.91 \pm 0.04)$. Although less dramatically (2.6-fold), mRNA for SMDF was also increased in neurons of the transgenic line \#2.

Axonal neuregulin activates two different signaling pathways in Schwann cells: the phosphatidylinositol kinase (PI3K) pathway and the RAS-MAPK pathway (Taveggia et al., 2005). To determine whether these pathways are activated in the PNS of NSE-hSMDF mice, the phosphorylation state of Akt and MAPK proteins was explored. Sciatic nerve homogenates from P20 NSE- $h S M D F^{+/-}$mice and their wild-type littermates were immunoblotted with anti-phospho-Akt and anti-phosphoMAPK-specific antibodies (see Material and Methods). Figure $1 c$ shows that the phosphorylation state of MAPK was increased in the transgenic mice, suggesting that overexpression of neuregulin in neurons produces sustained activation of the MAPK signaling pathway in Schwann cells. Akt (a downstream effector of PI3K) was also hyperphosphorylated in the transgenic mice, although less dramatically compared with MAPK (Fig. 1c). Together, these data suggest that overexpression of SMDF in neurons provokes accurately reflect the myelination state of axons (Muse et al., 2001). Therefore, we examined sciatic nerves of P20 NSE$h S M D F^{+/-}$mice in the electron microscope and determined the $g$-ratio (axon diameter/outer diameter of myelin sheath) as an estimate of myelin thickness. Surprisingly, except a slight decrease in the thickness of myelin for larger axons, no major changes in the myelin thickness occurred ( $g$-ratio, $0.67 \pm 0.004$ for wild type and $0.65 \pm 0.013$ for mutant; $n=4$ animals per genotype) (Fig. 2c). Therefore, our data show that overexpression of SMDF in PNS neurons provokes a reduction in myelin mRNAs and proteins but no corresponding deficit in myelination.

\section{Hyperproliferation of Schwann cells causes enlargement of peripheral nerves}

The lack of any reduction in myelin thickness in NSE-hSMDF mice raised the possibility that the apparent reduction in myelin gene expression might be a "dilution" effect caused by hypertrophy of other endoneurial compartments of the nerve. This idea was supported by the striking enlargement of nerve roots and dorsal root ganglia in NSE- hSMDF $F^{+/-}$mice (Fig. $3 a$ ). A detailed microscopic analysis showed that the space between myelinated axons was dramatically increased in the transgenic animals, espe- 
cially between P14 and P35 (Fig. 3b). Part of this increase is apparently caused by the expansion of the extracellular matrix, mainly proteoglycans and proteins (Fig. 3b) (see Fig. $8 c-e$ ). Although this expansion might explain the reduction in specific signal on Western blots (in which the loaded sample is normalized to total protein concentration), it cannot explain the dramatic decrease in the cognate $\mathrm{mR}$ NAs. The reduction of myelin-related $\mathrm{mR}$ NAs might, however, be explained by an increase in the number of nonmyelinating cells, for example, fibroblasts or nonmyelinating Schwann cells. To test this, we estimated by immunoblot the amount of ErbB3, a receptor that is expressed in both myelinating and nonmyelinating Schwann cells but not in fibroblasts (Jessen and Mirsky, 2005). Protein extracts from sciatic nerves of P20 NSE$h \mathrm{SMDF}^{+/-}$mice and wild-type littermates were analyzed on Western blots with a polyclonal anti-ErbB3 antibody. ErbB3 protein was upregulated in NSE-hSMDF ${ }^{+/-}$mice (Fig. 4a), suggesting that the Schwann cell population is expanded. This expansion seemed to involve preferentially nmSC, because GFAP, a reliable marker for nmSC (Jessen and Mirsky, 2005), was dramatically upregulated. Also supporting this interpretation, immunoreactivity for ApoE, which is expressed mainly in nmSC in the PNS (Boyles et al., 1985), was also greatly increased (Fig. 4a). Immunofluorescence microscopy confirmed that GFAP-positive $\left(\mathrm{GFAP}^{+}\right) \mathrm{nmSC}$ are much more numerous in NSE- hSMDF $F^{+/-}$mice (Fig. $4 b$ ). The sciatic nerves of wild-type mice were mainly occupied by myelinating Schwann cells $\left(\mathrm{S} 100 \beta^{+}\right.$, GFAP-negative, elongated nuclei), whereas in NSE$h S M D F^{+/-}$mice there were large clusters of nmSC separating the axons $\left(\mathrm{GFAP}^{+}\right.$, irregular shaped nuclei) (Fig. $4 b$ ). Toluidine blue staining of cross-sectioned nerves revealed that myelinated axons were less densely packed in NSE- hSMDF nerves compared with wild type, because the former contained abnormally large numbers of nonmyelinating cells in the inter-axonal space (Fig. 4c). However, no changes in the number of myelinating Schwann cells (Krox- $20^{+}$) per unit of nerve length could be observed (wild type, $100 \pm 19 \%$; transgenic, $108 \pm 16 \% ; n=3$ ) (Fig. $4 d$ ). Together, our data show that the enlargement of the nerves in the transgenic animals results from a large increase in the numbers of nmSC. To quantify the increase in cellularity and nerve thickness during postnatal development, cross-sections of sciatic nerves from NSE- $h S M D F^{+/-}$mice and wild-type littermates were stained with bisbenzimide (Hoechst nuclear stain) (Fig. 4e). Cross-sectional area and number of nuclei per cross-section were counted in confocal microscope images (Fig. $4 f, g$ ). As is shown in Figure $4 f$, the cross-sectional area of $\mathrm{P} 5$ transgenic sciatic nerves and wild-type littermates was essentially the same (wild type, $62.8 \pm 3.5 \mu \mathrm{m}^{2}, n=5$ animals; transgenic, $64.3 \pm 1.0 \mu \mathrm{m}^{2}, n=$ $5)$. At P20, the area of sciatic nerves in wild-type animals had increased $\sim 1.9$-fold compared with P5 $\left(116.2 \pm 6.8 \mu \mathrm{m}^{2}, n=5\right)$, whereas it had increased $\sim 3$.4-fold in the transgenic animals $\left(221.1 \pm 11.7 \mu \mathrm{m}^{2}, n=5\right)$. At P150, cross-sectional area was still larger in the transgenic mice relative to wild type $(297.2 \pm 1.4$ $\mu \mathrm{m}^{2}, n=5$ vs $260.8 \pm 1.7 \mu \mathrm{m}^{2}, n=5$, respectively). The number of nuclei per section (Fig. $4 g$ ) was also very similar at P5 in wildtype and transgenic animals $(458 \pm 26$ nuclei per section in wild a

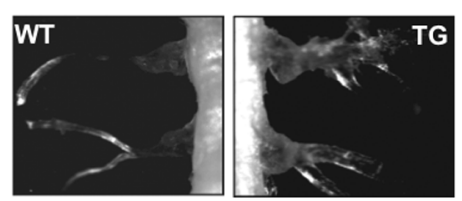
P5

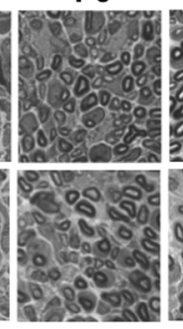

P14

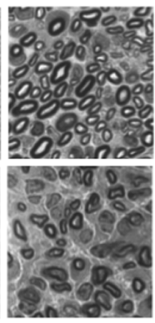

P20

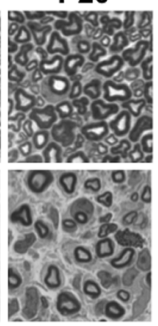

P35
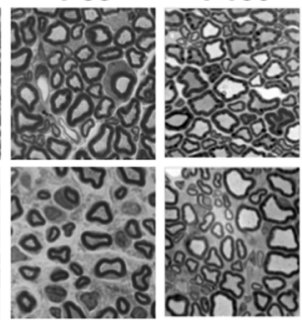

Figure 3. Transgene expression enlarge peripheral nerves. $\boldsymbol{a}$, Nerve roots and ganglia of P20 mutant NSE- hSMDF\# $1^{+/-}$mice (transgenic (TG)] are notably enlarged when compared with wild-type littermates (WT). $\boldsymbol{b}$, Mutant nerves (TG) show evident morphological alterations during postnatal myelination. Initial steps of myelination (P0 - P5) are indistinguishable in the NSEhSMDF mutants and wild-type littermates. In contrast, from P14 to P150, the number of myelinated axons per section is notably decreased in the mutant sciatic nerves. Images $(60 \times)$ of toluidine blue-stained sciatic nerves cross-sections were obtained from type, $n=5 ; 499 \pm 6$ nuclei per section in transgenics, $n=5$ ). However, by P20, the number of nuclei per section was much greater in NSE- $h S M D F^{+/-}$mice compared with wild type $(1859 \pm 89, n=5$ vs $527 \pm 26, n=5)$. At P150, the number of nuclei per section was still higher in the transgenic animals ( $1580 \pm 30, n=5$ vs $550 \pm 20, n=5$ ). Interestingly, the number of nuclei per unit area drops between P5 and P20 in wild-type nerves, probably as a consequence of increasing myelination and the consequent increase in Schwann cell volume (Fig. 4h). In contrast, in transgenic mice the density of nuclei does not fall between P5 and P20. After P20 (when myelination is complete), the number of nuclei per unit volume declines at a similar rate in both transgenic and wild-type nerves (Fig. 4h). Similar results (although less marked) were found in the independent transgenic line \#2 (supplemental Fig. S6, available at www.jneurosci.org as supplemental material).

Apart from Schwann cell numbers, an increase in the number and/or volume of axons could also theoretically contribute to the enlargement of nerves in mutant mice. To explore this possibility, we estimated axon density at P5, P20, and P150 in NSE$h S M D F^{+/-}$mice and their wild-type littermates. The density of myelinated axons was practically the same in transgenic and wildtype animals at P5 (Fig. 5a). However, at P20, the density of myelinated axons in transgenic nerves dropped to $60.9 \pm 7.6 \%$ that of wild type. However, allowing for the increase in nerve cross-sectional area $(\sim 1.9$-fold $)$, the number of axons per nerve is very similar in transgenic and wild-type animals ( $115 \pm 14 \%$ in transgenics relative to wild type). To explore the potential contribution of an increase in axonal volume to the increased nerve volume, we measured axon perimeter in P20 NSE- hSMDF $F^{+/-}$ and wild-type nerves. As is shown in Figure $5 b$, the distribution of axon perimeters in transgenic animals was clearly shifted toward smaller sizes compared with their wild-type littermates (Fig. 5b). Together, our data demonstrate that axons do not contribute to the increased thickness of peripheral nerves in NSE- hSMDF animals.

The augmented number of Schwann cells in NSE-hSMDF animals might be caused by increased proliferation and/or by a decrease in apoptosis in the $\mathrm{P} 5-\mathrm{P} 20$ period. Because apoptosis is already low in late postnatal nerves (Grinspan et al., 1996), we 
a

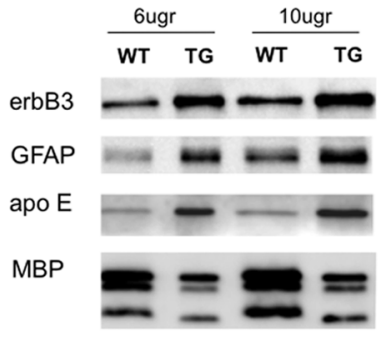

C

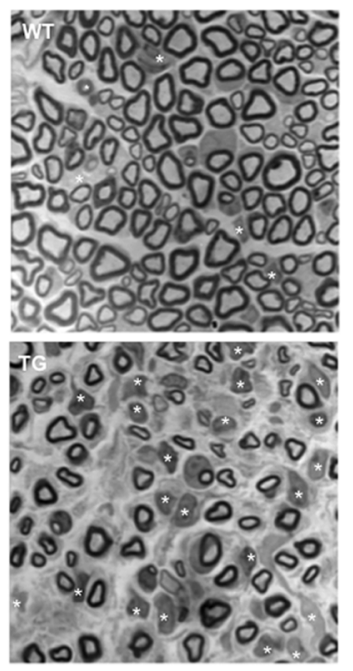

e

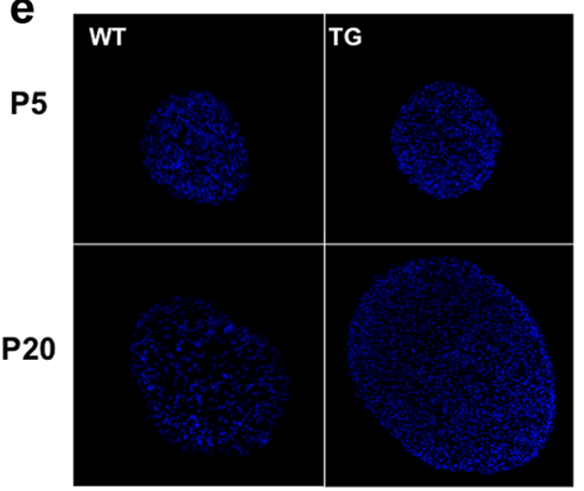

g

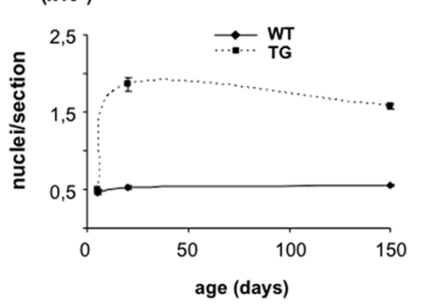

b
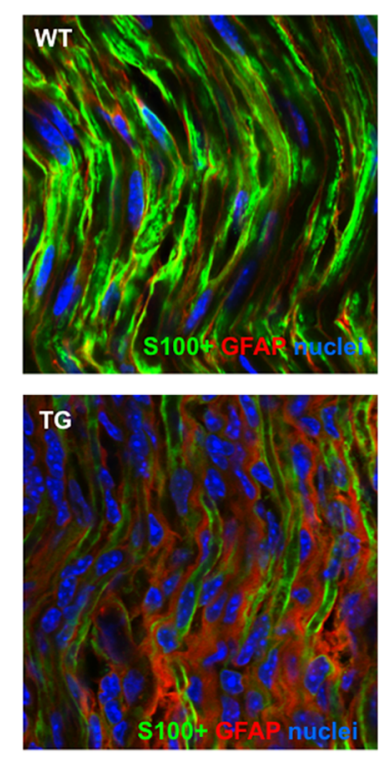

d

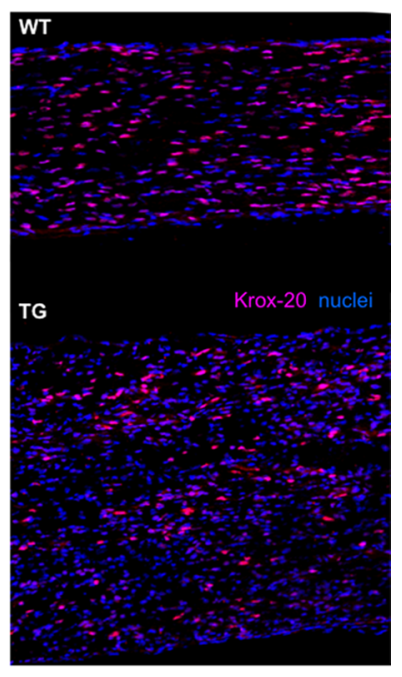

f
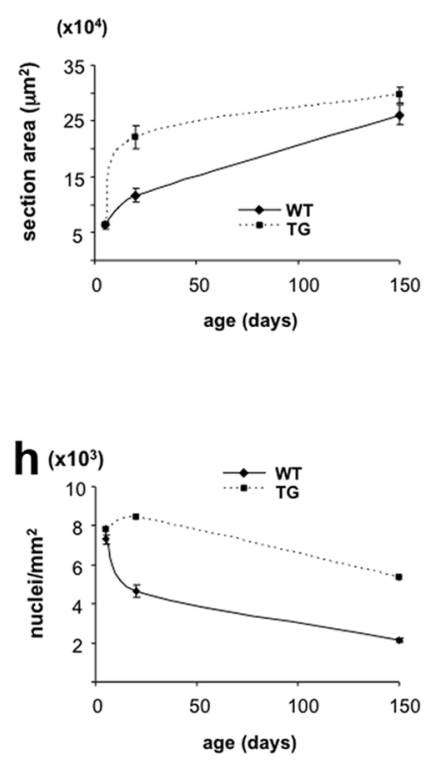

focused in putative changes in cell proliferation. BrdU ( $50 \mathrm{mg} / \mathrm{kg}$ body mass) was administered to NSE- $h S M D F^{+/-}$mice aged P5 or P14 (see Material and Methods). After three injections, the mice were killed, and sciatic nerve cells were dissociated and plated on poly-L-lysine- and laminin-coated coverslips. After cell attachment $(\sim 12 \mathrm{~h})$, cells were fixed and immunolabeled with anti-S100 $\beta$ and anti-BrdU antibodies. The BrdU labeling index (fraction of $S 100 \beta^{+}$Schwann cells that was $\mathrm{BrdU}^{+}$) is plotted in Figure $5 d$. At P5, the labeling index was substantially greater in the transgenic mice than in their wild-type littermates, indicating an increased proliferation rate in the transgenics. In contrast, at P14, the proliferation rates of transgenic and wild-type Schwann cells had converged. In the same line, the number of phospho-Histone $\mathrm{H} 3$-positive nuclei (a maker of mitosis) was found also increased in the P5 transgenic nerves (Fig.

\section{$\leftarrow$}

Figure 4. Nerve enlargement is caused by the hyperplasia of the nmSC during the postnatal development. $\boldsymbol{a}$, The amount of erbB3 protein (a Schwann cell marker) was notably increased, suggesting that there are more Schwann cells in the mutant nerves. GFAP (a protein expressed exclusively in $\mathrm{nmSC}$ ) is also clearly upregulated, suggesting that the expanded population of Schwann cells is mainly in a nonmyelinating state. In support of this tenet, the expression of ApoE was also increased. In contrast, MBP expression was notably downregulated in the mutant nerves. Protein extracts from NSE-hSMDF\# $1^{+/-}$and wild-type nerves were submitted to SDS-PAGE and immunoblotted with the indicated antibody. $\boldsymbol{b}$, Immunohistochemistry of mutant nerves: $\mathrm{nmSC}\left(\mathrm{GFAP}^{+}\right)$were barely observed in longitudinal sections of wild-type $\mathrm{P} 20$ sciatic nerves under the confocal microscope. In contrast, big clusters of nmSC segregate myelinated fibers $\left(\mathrm{S}_{100}{ }^{+}\right.$with sharp nucleus) in the nerves of mutant animals. c, Detailed inspection of toluidine blue-stained sections show that the number of cells dissociated from axons is increased in the mutant nerves (asterisks). $\boldsymbol{d}$, The number of myelinating cells is not increased in the mutant nerves. Although the density of Krox- $20^{+}$nuclei is notably decreased in mutant nerves, the number of Krox- $20^{+}$ nuclei per unit of nerve length is similar in wild-type and transgenic nerves. $\boldsymbol{e}$, Transgene expression increases dramatically the number of nucleated cells in the P20 mutant nerves. Images obtained with a confocal microscope from sciatic nerve sections stained with bisbenzimide of NSE-hSMDFH1 $1^{+/-}$ mice [transgenic (TG)] and wild-type littermates (WT). $\boldsymbol{f}$, Sciatic nerve section area in wild-type and mutant mice during postnatal development. The nerve section was estimated for at least five animals with the indicated age. $\boldsymbol{g}$, The number of cells (nuclei) is dramatically increased in the mutant mice. Nuclei were counted from cross-sections stained with bisbenzimide using NIH ImageJ software. The number of nuclei per section was estimated for at least five animals of the indicated age. $\boldsymbol{h}$, In contrast to wild types, mutants do not show the postnatal decrease in nuclei density that occurs during myelination. From P20 to P150, the drop in nuclei density (slope) is very similar in mutants and wild-type littermates, suggesting that the main alterations of mutant nerves are produced during the postnatal development. Data are given as mean \pm SE. 
$5 e, f)$. Therefore, the hypercellularity of transgenic nerves is caused mainly by the hyperproliferation of Schwann cells between P5 and P14.

In summary, our data suggest that the enlargement of sciatic nerves in the NSE-hSMDF mice is the consequence of the in vivo mitogenic effect of type III- $\beta 3$ neuregulin (SMDF) on nonmyelinating Schwann cells.

\section{Remak bundle degeneration and myelination}

It has been shown that small-sized axon segregation in the Remak bundles is controlled by type III neuregulins (Taveggia et al., 2005). To investigate whether the type III- $\beta 3$ neuregulin isoform also plays a role in small-caliber axon ensheathment and segregation, we obtained electron microscope images of sciatic nerves from P20 NSE- hSMDF ${ }^{+/-}$mice and wild-type littermates. As is shown in Figure 6, the structure of the Remak bundles in the mutant nerves is dramatically altered. In contrast to wild type (Fig. $6 a, b$ ), most of the small-caliber axons of the transgenic mice remain unsegregated within the Schwann cell cytoplasm, forming a single fascicle of axons located in a large pocket (Fig. $6 c, d$ ). However, the number of axons per Remak bundle remains unaltered. A detailed quantification of the number of axons per pocket and total axons per bundle in mutant and wild-type nerves is shown in Figure $6, e$ and $f$.

Interestingly, in mutant bundles, the nmSC is apparently "extruded" from the fascicle and ensheathes the whole pack of axons as if it were a single large-caliber axon, in what resembles a premyelinating complex. Strikingly, a significant number of these atypical Remak bundles ( 20\%) develop an electron-dense structure surrounding the axon fascicle resembling a compact myelin sheath (Fig. $6 g-j$ ). Indeed, the high-resolution structure of this electron-dense material in the electron microscope was indistinguishable from compact myelin around single axons (Fig. $6 k, l$ ). In longitudinal sections, myelination seems to be continuous along some axon bundles (Fig. $6 \mathrm{~m}$ ), whereas in others myelination is only partial (Fig. 6n). To our surprise, no "normal" Remak bundles could be found in P20 transgenic nerves (supplemental Fig. S7, available at www.jneurosci.org as supplemental material). Although much less dramatically, Remak bundle degeneration and myelination was also observed in transgenic line \#2 (data not shown). Together, our data suggest that the expression of type III- $\beta 3$ neuregulin in small-caliber axons, in addition to stimulating Schwann cell proliferation, reprograms the nmSC into a myelinating phenotype and results in the myelination of whole Remak bundles as single units.

Unmyelinated small-diameter axons in normal Remak bundles have slow conduction velocities $(<1 \mathrm{~m} / \mathrm{s})$ and can be identype; TG, transgenic.

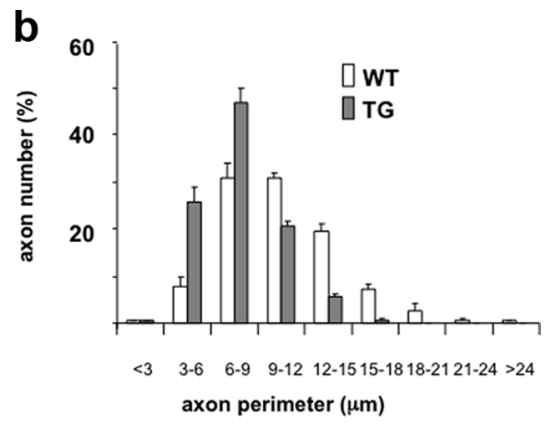

d

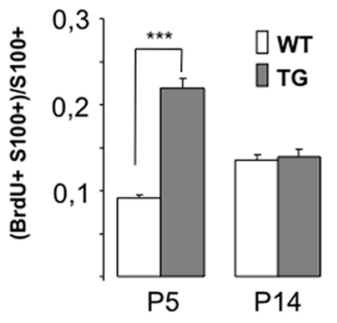

f

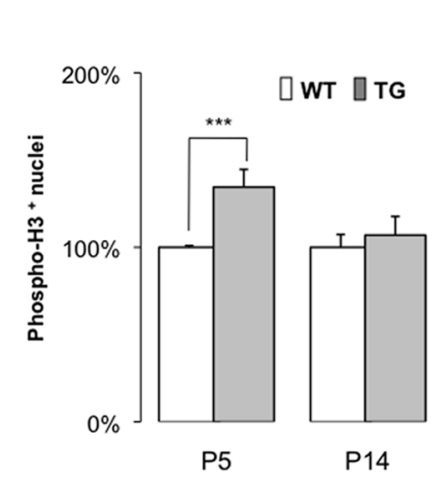

Figure 5. Increased Schwann proliferation rate but not axon size or density drives to nerve enlargement. $\boldsymbol{a}$, Axonal density is lower in the mutant mice, suggesting that an increase in the number of axons does not contribute to nerve enlargement. $\boldsymbol{b}$, The largement. Axon density and size were estimated in optical and EM images obtained from sections of two or more sciatic nerves 作 to $\mathrm{S} 100^{+}$Schwann cells (see Materials and Methods). A notable increase in the Schwann cell proliferation in the mutants could be observed at P5 but not at P14. e, $\boldsymbol{f}$, Similar results were obtained when the mitotic index (phospho-Histone $\mathrm{H} 3{ }^{+}$) was estimated. Two to three animals per genotype and age were used. Data are given as mean $\pm \mathrm{SE}\left({ }^{* * *} p<0.0001\right.$, Student's $t$ test.). WT, Wild

tified as "C-fibers" in recordings of compound action potentials along sciatic nerves. C-fibers have been shown to be involved in temperature sensing, pain, mechanical transduction, and itching. The proper ensheathment and segregation of small axons in individual pockets of the nmSC cytoplasm is critical for nerve function (Taveggia et al., 2005). To explore whether the atypical myelination and aberrant segregation of small-caliber axons in the abnormal Remak bundles of NSE- $h S M D F$ mice affects nerve conduction velocity, sciatic nerves from adult NSE- $h S M D F^{+/-}$ mice and wild-type littermates were removed, and compound action potentials were recorded (see Materials and Methods). We found that myelination of Remak bundles did not increase the nerve conduction velocity in the C-fibers. In fact, a significant decrease in the conduction velocity was found (Fig. $7 a, b$ ). Surprisingly, and although myelination of individual large-diameter 


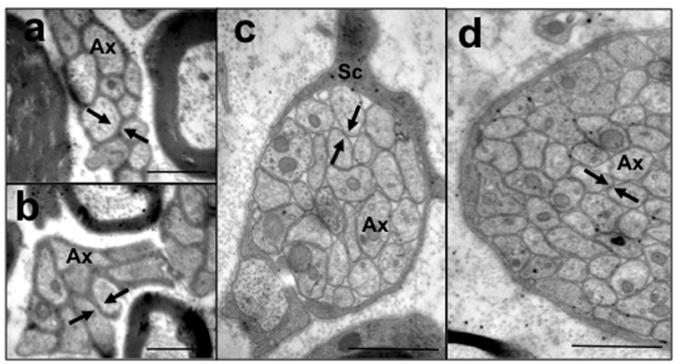

e

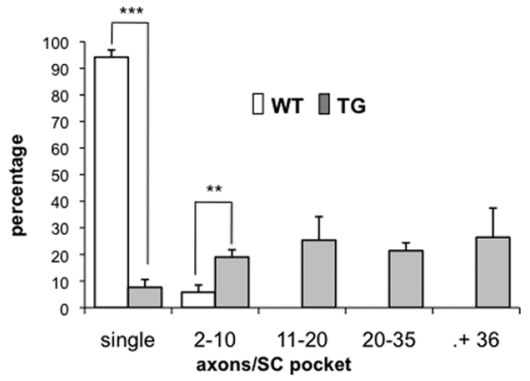

$\mathbf{f}$
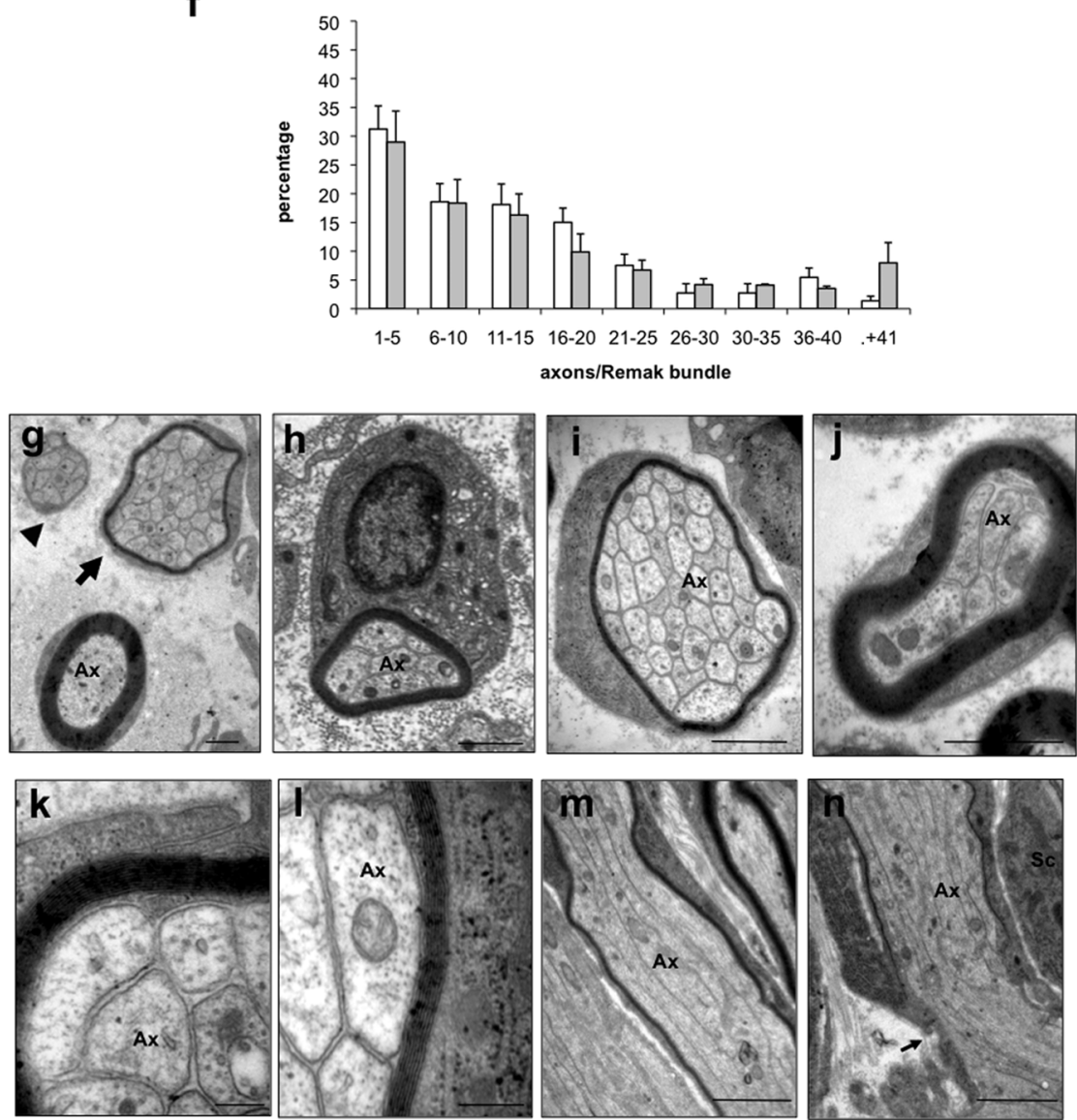

Figure 6. Transgene expression disrupts small-diameter axon segregation and induces Remak bundle myelination. $\boldsymbol{a}, \boldsymbol{b}$, Transmission EM images obtained from P20 wild-type mice showing that small-sized axons (Ax) are segregated by the cytoplasm of the nmSC in the Remak bundle (arrows). Scale bars, $1 \mu \mathrm{m}$. c, d, No cytoplasm segregates small-sized axons in the NSE-hSMDF mice (arrows). In these nerves, the Schwann cell (Sc) remains outside of the bundle ensheathing the whole pack of axons. Scale bars, $1 \mu \mathrm{m} . \boldsymbol{e}$, Distribution of axons per pocket is profoundly modified in mutant nerves. In contrast to wild type, in mutant nerves, very few axons are found in individual pockets. $f$, In contrast, the number axons per Remak bundle is not changed. More than 170 bundles from four $P 20$ different animals $(n=$ 4) were counted per genotype. Data are given as mean $\pm \operatorname{SE}\left({ }^{* *} p=0.0041,{ }^{* * *} p<0.0001\right.$, Student's $t$ test.). $\boldsymbol{g}$, With these atypical Remak bundles (arrowhead), others coexist in which the ensheathing Schwann cell has developed a myelin membrane wrapping the whole bundle (arrow). The total area of the myelinated bundle is similar to the area of myelinated axons. Scale bar, $1 \mu \mathrm{m}$. $\boldsymbol{h}$-j, Myelinated bundles with increased magnification. Scale bars, $1 \mu \mathrm{m} . \boldsymbol{k}, \boldsymbol{l}$, High-power EM images of mutant Remak bundles. The membrane wrapping the bundle is structurally indistinguishable of a myelin sheath. Scale bars, $0.2 \mu \mathrm{m} . \boldsymbol{m}, \boldsymbol{n}$, EM images of longitudinal sections of mutant nerves showing that, whereas some bundles seem completely myelinated $(\boldsymbol{m})$, myelination is not always continuous along other bundles (n, arrow). Scale bars, $1 \mu \mathrm{m}$. WT, Wild type; TG, transgenic. axons is basically normal (Fig. $2 c$ ), nerve conduction velocity of myelinated single fibers was also decreased in the transgenic mice (Fig. $7 c, d$ ).

\section{Sustained neuregulin axon-glial signaling induces the development of neurofibroma-like lesions and peripheral nerve sheath tumors}

Type I neurofibromatosis is a genetic disease caused by the inactivation of the $N f 1$ gene (Cichowski and Jacks, 2001; Zhu et al., 2002). Neurofibromas are benign tumors that enlarge nerves (Zhu et al., 2002; Ling et al., 2005). Histology of neurofibroma is characterized by Schwann cell hyperplasia, dissociation of Schwann cells from axons, increased endoneurial collagen matrix, and mast cell accumulation (Ling et al., 2005). As has been introduced previously, NSE-hSMDF ${ }^{+/-}$transgenic nerves displayed several traits of neurofibroma. First, at early postnatal ages (P20), all transgenic mice show an obvious enlargement of nerve roots (Fig. 3a), resembling plexiform neurofibromas (Zhu et al., 2002). Enlargement was also observed in the dorsal root ganglia, trigeminal ganglia, and sciatic and brachial nerves (data not shown). Moreover, the number of Schwann cells (mainly dissociated and nonmyelinating Schwann cells) in transgenic nerves was also noticeably increased (Fig. $4 d, f$ ). To investigate further the neurofibroma-like phenotype of NSE$h S M D F^{+/-}$mice, we asked whether the endoneurial collagen matrix of mutant sciatic nerves was increased, as in neurofibroma. We stained sections of sciatic nerves with Gomori's trichrome stain, a histological reagent that renders extracellular collagen green and cell cytoplasm purple. In wild-type mice, collagen (green) was primarily restricted to the perineum, being very faint in the endoneurium (Fig. $8 a$ ). In contrast, the transgenic nerve showed a rich green staining of the endoneurium (Fig. 8b), suggesting an increase in collagen deposition. In electron microscope images, the myelinated axons of the transgenic nerves were also separated by abnormally expanded extracellular matrix highly enriched in collagen fibrils (Fig. $8 c-e$, arrows).

Five to $10 \%$ of patients with plexiform neurofibroma develop malignant peripheral nerve sheath tumors, an aggressive type of cancer that decreases enormously life expectance and quality. To know whether the overactivation of the neuregulin pathway promotes as well the apparition of peripheral nerve tumors, we aged NSE-hSMDF $F^{+/-}$transgenic mice 
and littermates. Approximately 1 in 10 NSE- $h S M D F^{+/-}$mice develop big tumors in the peripheral nervous system producing neurological symptoms (Fig. $9 a$ ). Tumors could be identified in both transgenic lines, mainly between 6 and 24 months of age. In mouse line \#1, 12.4\% of transgenic animals (11 of 89) showed symptomatic big peripheral nerve tumors, whereas no tumors were detected in wild-type littermates of the same age (0 of 78). In mouse line \#2, 10.5\% transgenic mice showed peripheral nerve tumors (4 of 38 ), whereas no tumors were found in its wild-type littermates ( 0 of 29). In most cases, the tumors were clearly associated with peripheral nerves and/or ganglia (Fig. 9b-e). Immunohistochemistry studies showed that tumors express $S 100 \beta$ and GFAP (Fig. 9f), suggesting a Schwann cell origin. Supporting this view, mRNA for P0, MBP, and CNPase could also be detected (data not shown). Together, our data show that the sustained axon-glial signaling at the Remak bundle produces neurofibroma-like lesions that in some cases are transformed into peripheral nerve sheath tumors.

\section{Discussion}

Members of the neuregulin family are abundantly expressed in the nervous system in which they are involved in pivotal steps of neuron and glial cell biology and development (Meyer et al., 1997; Jessen and Mirsky, 2002; Nave and Schwab, 2005). The Neuregulin 1 gene encodes for at least 15 different isoforms, grouped in three different types. Type III isoforms (but no type I or II) have been shown to regulate the myelination of PNS neurons (Nave and Salzer, 2006). There are at least two different type III neuregulins. The first type III isoform reported was the type III- $\beta 3$, also known as SMDF. This neuregulin is highly expressed in the sensory and motor neurons of the dorsal root ganglia (Ho et al., 1995) and segregated into lipid rafts, membrane platforms pivotal for axon-glial signaling (Cabedo et al., 2002, 2004; Decker and ffrench-Constant, 2004).

It was shown recently that type III neuregulins regulate the thickness of the myelin sheath (Michailov et al., 2004). In addition, the artificial expression of one of these isoforms (the III- $\beta 1 \mathrm{a}$ isoform) in unmyelinated axons converts them to a myelinated phenotype, suggesting that threshold levels of neuregulin determines the myelination status of the axon (Taveggia et al., 2005). Here we show that, in contrast to type III- $\beta 1 \mathrm{a}$, in vivo overex-
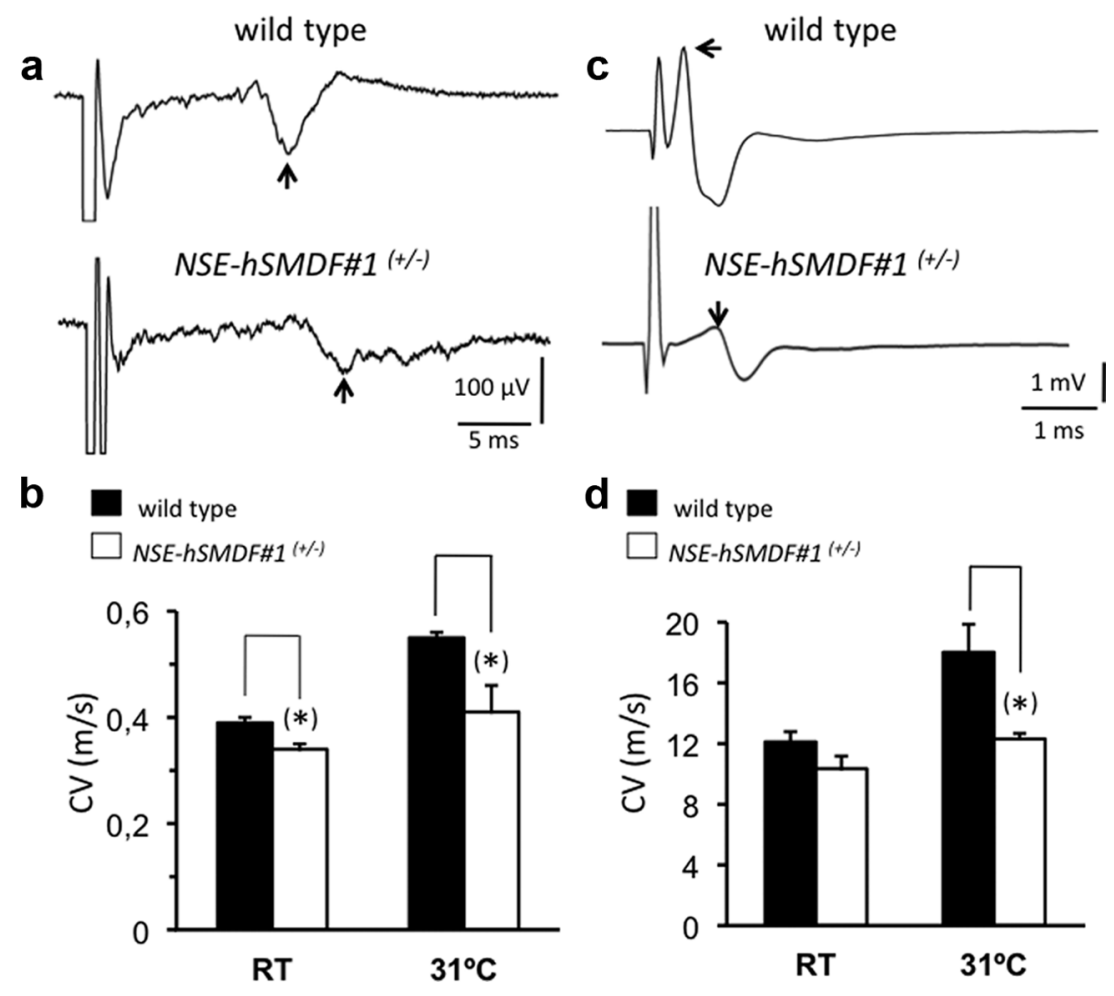

Figure 7. Nerve conduction velocity of C-fibers is decreased in the mutant mice. $\boldsymbol{a}$, Typical recording of compound action potential from the sciatic nerves of NSE- hSMDF\# $1^{+/-}$and wild-type littermates. Arrows indicate signal from C-fibers. $\boldsymbol{b}$, Quantification at room temperature (RT) and $31^{\circ} \mathrm{C}$ shows that $\mathrm{C}$-fiber conduction velocity (CV) is decreased in the mutant mice. $\boldsymbol{c}, \boldsymbol{d}$, Conduction velocity of myelinated fibers (arrows) is also reduced, probably as a consequence of the reduced diameter of axons in the transgenic animals. $n=4$ animals for RT and $n=2$ for $31^{\circ} \mathrm{C}$ recordings. Data are given as mean $\pm \operatorname{SE}\left({ }^{*} p<0.05\right.$, Student's $t$ test).
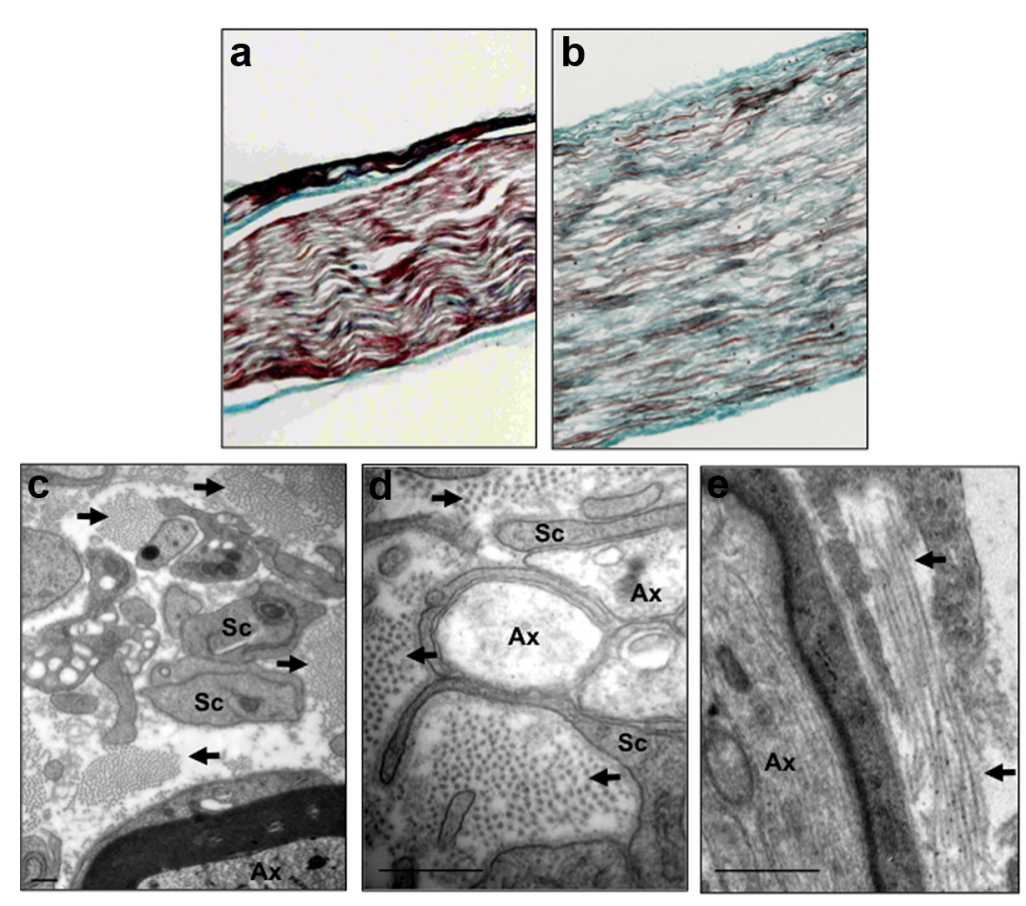

Figure 8. Accumulation of extracellular collagen in the mutant nerves. $\boldsymbol{a}$, Gomori's trichrome staining of wild-type nerves shows that collagen (green) is concentrated in the perineurum and barely detectable in the endoneurium, which is mainly occupied by cytoplasm (purple). $\boldsymbol{b}$, In contrast, endoneurium of mutant nerves is widely stained in green, suggesting that collagen accumulates in the extracellular matrix. $\boldsymbol{c}, \boldsymbol{d}$, High-power EM images obtained from cross-sections of mutant animals showing large deposits of collagen fibrils in the extracellular space. $\boldsymbol{e}$, Collagen fibrils can be also observed in longitudinal sections of mutant nerves. Ax, Axons; Sc, Schwann cells. Scale bars, $0.5 \mu \mathrm{m}$. 


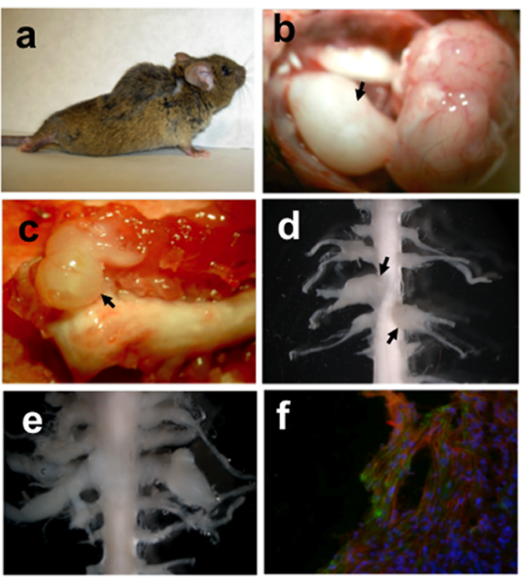

g
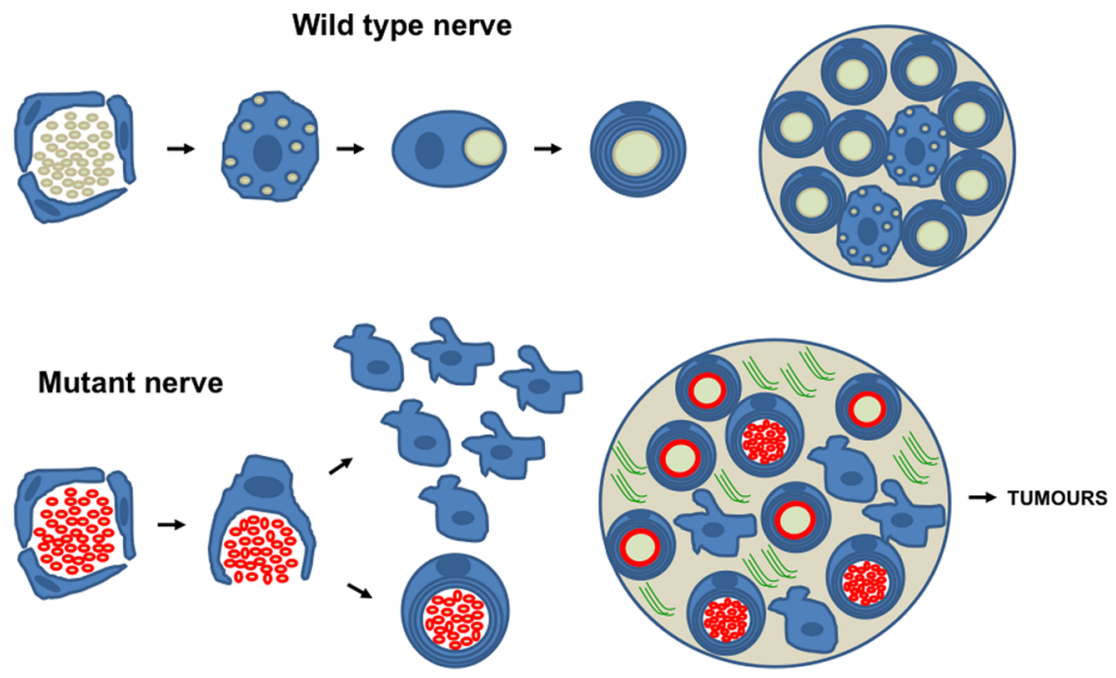
:\% Small size axons

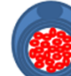

Myelinated Remak bundle

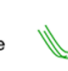

Collagen fibrils

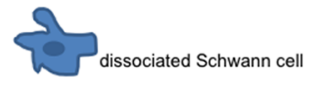

Figure 9. Sustained neuregulin signaling induces tumorigenesis. $\boldsymbol{a}$, Tumors produce neurological symptoms, such as limb paralysis and postural alterations. $\boldsymbol{b}$, A big tumor in the trigeminal ganglia in an NSE- hSMDF mutant mouse. $\boldsymbol{c}$, One of the tumors originated in a cervical nerve root of the spinal cord. $\boldsymbol{d}$, Tumors originated in the nerve roots and dorsal ganglia compressing the spinal cord in transgenic animals. $\boldsymbol{e}$, Multiple enlargement of nerves and ganglia at the cervical and dorsal level of the spine. $\boldsymbol{f}$, Immunohistochemistry showing that tumors express $S 100 \beta$ (red) and GFAP (green). Nuclei were stained with bisbenzimide (blue). $\boldsymbol{g}$, Model for the development of nerves in wild-type and mutant mice. Top, During the postnatal development of wild-type nerves, Schwann cells ensheathe and myelinate large-diameter axons. Small-sized axons remain ensheathed but unmyelinated in the Remak bundles (adapted from Jessen and Mirsky, 2005). Bottom, Overexpression of SMDF (red) has a mitogenic effect on Schwann cells inducing hyperproliferation. SMDF also induces a phenotypic change of the nmSC toward a myelinating phenotype, which results in the myelination of the bundles.

pression of type III- $\beta 3$ isoform (SMDF) does not increase myelin thickness in the PNS. Although these studies were performed using different promoter constructs (NSE and Thy1), given their broad neuronal expression in many neurons (Morris et al., 1983; Kollias et al., 1987; Forss-Petter et al., 1990; Vega et al., 1990) and their similar postnatal expression pattern (supplemental Fig. S9, available at www.jneurosci.org as supplemental material), these are probably bone fide differences in neuregulin isoform activity. We do not have a molecular explanation for the dissimilar behaviors of the III- $\beta 1 \mathrm{a}$ and III- $\beta 3$ isoforms. However, it might be significant that the type III- $\beta 3$ isoform lacks the transmembrane and cytoplasmic domains located at the $\mathrm{C}$ terminus of type III$\beta 1$ a. It has been suggested that this domain might signal back to the cell nucleus (Bao et al., 2003); thus, the possibility exists that the increase in myelin thickness induced by type III- $\beta 1$ a could require the coexpression of an additional (yet unidentified) growth factor induced by back-signaling.

Although it is well known that neuregulins are mitogenic factors for Schwann cells in vitro (Stewart et al., 1991; Dong et al., 1995; Levi et al., 1995; Maurel and Salzer, 2000), there has been no conclusive in vivo evidence (Jessen and Mirsky, 2005). By using BrdU uptake experiments and phospho-Histone 3 immunohistochemistry, we have shown that nerve enlargement in NSE-SMDF mice is caused by early postnatal hyperproliferation of nmSC, supporting that SMDF is a mitogenic factor for Schwann cells in vivo. The increased proliferation in the transgenic nerves is transient, not persisting after P14. The reason for this is not clear because expression of the SMDF transgene continues after P14 and even during adulthood (data not shown). One possibility is that stability of SMDF, ErbB2, or ErbB3 proteins might decrease after P14. However, this seems unlikely because PI3K and MAPK pathways remain hyperactivated in P20 transgenic nerves. Another possibility is that Schwann cell proliferation is self-limited, through a balance between the relative rates of supply and demand of SMDF and other mitogens: as Schwann cell number increases, so might their rate of consumption/degradation of SMDF. There is evidence that such a mechanism involving PDGF regulates oligodendrocyte precursor proliferation and ultimate cell number in the developing CNS (Calver et al., 1998; van Heyningen et al., 2001). Other explanations are, however, also possible.

It is well established that myelination depends on axon diameter (Friede and Bischhausen, 1982). Small-caliber axons $(<1 \mu \mathrm{m})$ are not large enough to be myelinated and remain grouped in packs and ensheathed by the nmSC in Remak bundles. It has been suggested that neuregulins contribute to the correct segregation of small-diameter axons in the Remak bundle (Taveggia et al., $2005)$. Here we show that overexpression of type III- $\beta 3$ neuregulin in neurons has dramatic effects on the organization of Remak bundles. The small-caliber axons are not segregated in individual pockets in the nmSC cytoplasm as they normally are but are compacted into a tight fascicle that is ensheathed by compact myelin, as if it were a single large-diameter axon. The conduction velocity of abnormally myelinated Remak bundles is not increased; on the contrary, we found that their conduction velocity was decreased relative to normal C-fibers. This is presumably related to the fact that only the peripheral axons of the bundle are in contact with the myelin membrane, the majority in the interior of the bundle remaining unmyelinated. Even for those axons that are in contact with myelin, contact is only partial. Furthermore, myelination is not continuous along the longitudinal axis of the 
bundles, leaving large parts of the axons unmyelinated (although ensheathed by a single nmSC wrap) (Fig. 6n). This by itself would be expected to severely hamper saltatory conduction.

It has been shown previously that adequate segregation of C-fibers in individual cytoplasmic pockets is pivotal for proper conduction (Taveggia et al., 2005). Because the axons in the aberrant bundles are not individually segregated but close to or in contact with one another, this also would be expected to interfere with conduction. Interestingly, the conduction velocity of myelinated individual fibers was also decreased in the mutant nerves (Fig. $7 c, d$ ). Because there is not an obvious change in the myelin thickness, we believe that this is probably provoked by a downward shift in the distribution of axon caliber size (Fig. 5b). In support of this view, we also found a significant decrease in the current amplitude for the component of myelinated fibers (supplemental Fig. S8, available at www.jneurosci.org as supplemental material).

During our study, we observed that NSE- hSMDF ${ }^{+/-}$mice develop several phenotypic traits of neurofibromatosis. One of the most remarkable observations was that they develop enlarged nerve roots and peripheral ganglia (Fig. $3 a$ ) with a striking similarity to human plexiform neurofibromas and animal models of the disease (Cichowski et al., 1999; Zhu et al., 2002). A detailed microscopic study shows that nerve enlargement is mainly caused by the hyperplasia of nmSC. Interestingly, it has been suggested that the induction of abnormal proliferation of nmSC triggers neurofibroma formation. In $\mathrm{Nf1}^{\text {flox/-}} ; \mathrm{POA}-\mathrm{cre}^{+}$mice, Zheng et al. (2008) have shown that $N f 1$ deficiency does not cause hyperproliferation or tumorigenesis during the early postnatal period. The only differential trait found at this time is the existence of abnormal Remak bundles. Akin to NSE-hSMDF mice, Remak bundles in these animals contain poorly segregated axons and, in some cases, myelinated structures containing both smalland large-diameter axons. These authors suggest that neurofibromas that originate at later stages in $\mathrm{Nf1}^{\text {flox } /-} ; \mathrm{POA}_{-} \mathrm{cre}^{+}$mice are caused by the hyperproliferation of nmSC in the postnatal nerves. Our own data show that sustained overexpression of SMDF also induces nmSC hyperproliferation and disorganization of Remak bundles. As in the case of type I neurofibromatosis, Remak bundle degeneration also facilitates the development of big peripheral nerve sheath tumors. Whether there is link between both pathological mechanisms needs to be further explored.

The NRG1-erbB pathway is hyperactivated in many epithelial tumors (Alroy and Yarden, 2000). Interestingly, the ectopic expression of the type II neuregulin GGF $\beta 3$ in myelinating Schwann cells ( $P 0-G G F \beta 3$ mice) induced as well the development of hypertrophic neuropathies and malignant peripheral nerve sheath tumors (Huijbregts et al., 2003). In the same line, the overexpression of ErbB1 receptor in Schwann cells (CNPepidermal growth factor receptor mice) provokes peripheral nerve tumors (Ling et al., 2005). Moreover, the gene encoding for one of the neuregulin receptors ( $E r b B 2$ gene) is frequently amplified in human malignant peripheral nerve sheath tumors, a cancer type derived from plexiform neurofibroma (Storlazzi et al., 2006). Although the molecular link between ErbB receptor activation and neurofibroma development needs to be further clarified, it is interesting to point out that neuregulin binding to ErbB receptors elicits the activation of the MAPK pathway, which is believed to be responsible for hyperproliferation in the Nf1deficient Schwann cells (Cichowski and Jacks, 2001).

In summary, our data support the view that the sustained activation of nmSC by axon-derived neuregulin in Remak bundles can contribute to peripheral nerve tumorigenesis (Fig. 9g) and points toward the inhibition of the axon-glial signaling pathway as a putative therapeutic target for the treatment of peripheral nervous system tumors.

\section{References}

Alroy I, Yarden Y (2000) Biochemistry of HER2 oncogenesis in breast cancer. Breast Dis 11:31-48.

Bao J, Wolpowitz D, Role LW, Talmage DA (2003) Back signaling by the Nrg-1 intracellular domain. J Cell Biol 161:1133-1141.

Boyles JK, Pitas RE, Wilson E, Mahley RW, Taylor JM (1985) Apolipoprotein $\mathrm{E}$ associated with astrocytic glia of the central nervous system and with nonmyelinating glia of the peripheral nervous system. J Clin Invest 76:1501-1513.

Cabedo H, Luna C, Fernandez AM, Gallar J, Ferrer-Montiel A (2002) Molecular determinants of the sensory and motor neuron-derived factor insertion into plasma membrane. J Biol Chem 277:19905-19912.

Cabedo H, Carteron C, Ferrer-Montiel A (2004) Oligomerization of the sensory and motor neuron-derived factor prevents protein O-glycosylation. J Biol Chem 279:33623-33629.

Calver AR, Hall AC, Yu WP, Walsh FS, Heath JK, Betsholtz C, Richardson WD (1998) Oligodendrocyte population dynamics and the role of PDGF in vivo. Neuron 20:869-882.

Cichowski K, Jacks T (2001) NF1 tumor suppressor gene function: narrowing the GAP. Cell 104:593-604.

Cichowski K, Shih TS, Schmitt E, Santiago S, Reilly K, McLaughlin ME, Bronson RT, Jacks T (1999) Mouse models of tumor development in neurofibromatosis type 1 . Science 286:2172-2176.

Decker L, ffrench-Constant C (2004) Lipid rafts and integrin activation regulate oligodendrocyte survival. J Neurosci 24:3816-3825.

Dong Z, Brennan A, Liu N, Yarden Y, Lefkowitz G, Mirsky R, Jessen KR (1995) Neu differentiation factor is a neuron-glia signal and regulates survival, proliferation, and maturation of rat Schwann cell precursors. Neuron 15:585-596.

Falls DL (2003) Neuregulins: functions, forms, and signaling strategies. Exp Cell Res 284:14-30.

Forss-Petter S, Danielson PE, Catsicas S, Battenberg E, Price J, Nerenberg M, Sutcliffe JG (1990) Transgenic mice expressing beta-galactosidase in mature neurons under neuron-specific enolase promoter control. Neuron 5:187-197.

Friede RL, Bischhausen R (1982) How are sheath dimensions affected by axon caliber and internode length? Brain Res 235:335-350.

Fruttiger M, Calver AR, Krüger WH, Mudhar HS, Michalovich D, Takakura N, Nishikawa S, Richardson WD (1996) PDGF mediates a neuronastrocyte interaction in the developing retina. Neuron 17:1117-1131.

Fruttiger M, Karlsson L, Hall AC, Abramsson A, Calver AR, Boström H, Willetts K, Bertold CH, Heath JK, Betsholtz C, Richardson WD (1999) Defective oligodendrocyte development and severe hypomyelination in PDGF-A knockout mice. Development 126:457-467.

Grinspan JB, Marchionni MA, Reeves M, Coulaloglou M, Scherer SS (1996) Axonal interactions regulate Schwann cell apoptosis in developing peripheral nerve: neuregulin receptors and the role of neuregulins. J Neurosci 16:6107-6118.

Haurogné K, Bach JM, Lieubeau B (2007) Easy and rapid method of zygosity determination in transgenic mice by SYBR Green real-time quantitative PCR with a simple data analysis. Transgenic Res 16:127-131.

Ho WH, Armanini MP, Nuijens A, Phillips HS, Osheroff PL (1995) Sensory and motor neuron-derived factor. A novel heregulin variant highly expressed in sensory and motor neurons. J Biol Chem 270:14523-14532.

Huijbregts RP, Roth KA, Schmidt RE, Carroll SL (2003) Hypertrophic neuropathies and malignant peripheral nerve sheath tumors in transgenic mice overexpressing glial growth factor $\beta 3$ in myelinating Schwann cells. J Neurosci 23:7269-7280.

Jessen KR, Mirsky R (2002) Signals that determine Schwann cell identity. J Anat 200:367-376.

Jessen KR, Mirsky R (2005) The origin and development of glial cells in peripheral nerves. Nat Rev Neurosci 6:671-682.

Kollias G, Spanopoulou E, Grosveld F, Ritter M, Beech J, Morris R (1987) Differential regulation of a Thy-1 gene in transgenic mice. Proc Natl Acad Sci U S A 84:1492-1496.

Le N, Nagarajan R, Wang JY, Svaren J, LaPash C, Araki T, Schmidt RE, Milbrandt J (2005) Nab proteins are essential for peripheral nervous system myelination. Nat Neurosci 8:932-940. 
Levi AD, Bunge RP, Lofgren JA, Meima L, Hefti F, Nikolics K, Sliwkowski MX (1995) The influence of heregulins on human Schwann cell proliferation. J Neurosci 15:1329-1340.

Ling BC, Wu J, Miller SJ, Monk KR, Shamekh R, Rizvi TA, Decourten-Myers G, Vogel KS, DeClue JE, Ratner N (2005) Role for the epidermal growth factor receptor in neurofibromatosis-related peripheral nerve tumorigenesis. Cancer Cell 7:65-75.

Maurel P, Salzer JL (2000) Axonal regulation of Schwann cell proliferation and survival and the initial events of myelination requires PI 3-kinase activity. J Neurosci 20:4635-4645.

Meyer D, Yamaai T, Garratt A, Riethmacher-Sonnenberg E, Kane D, Theill LE, Birchmeier C (1997) Isoform-specific expression and function of neuregulin. Development 124:3575-3586.

Michailov GV, Sereda MW, Brinkmann BG, Fischer TM, Haug B, Birchmeier C, Role L, Lai C, Schwab MH, Nave KA (2004) Axonal neuregulin-1 regulates myelin sheath thickness. Science 304:700-703.

Mitrecić D, Huzak M, Curlin M, Gajović S (2005) An improved method for determination of gene copy numbers in transgenic mice by serial dilution curves obtained by real-time quantitative PCR assay. J Biochem Biophys Methods 64:83-98.

Morris RJ, Barber PC, Beech J, Raisman G (1983) The distribution of Thy-1 antigen in the PNS of the adult rat. J Neurocytol 12:1017-1039.

Morrissey TK, Levi AD, Nuijens A, Sliwkowski MX, Bunge RP (1995) Axoninduced mitogenesis of human Schwann cells involves heregulin and p185erbB2. Proc Natl Acad Sci U S A 92:1431-1435.

Muse ED, Jurevics H, Toews AD, Matsushima GK, Morell P (2001) Parameters related to lipid metabolism as markers of myelination in mouse brain. J Neurochem 76:77-86.

Nave KA, Salzer JL (2006) Axonal regulation of myelination by neuregulin 1. Curr Opin Neurobiol 16:492-500.

Nave KA, Schwab MH (2005) Glial cells under remote control. Nat Neurosci 8:1420-1422.
Schroering A, Carey DJ (1998) Sensory and motor neuron-derived factor is a transmembrane heregulin that is expressed on the plasma membrane with the active domain exposed to the extracellular environment. J Biol Chem 273:30643-30650.

Sherman DL, Brophy PJ (2005) Mechanisms of axon ensheathment and myelin growth. Nat Rev Neurosci 6:683-690.

Stewart HJ, Eccleston PA, Jessen KR, Mirsky R (1991) Interaction between cAMP elevation, identified growth factors, and serum components in regulating Schwann cell growth. J Neurosci Res 30:346-352.

Storlazzi CT, Brekke HR, Mandahl N, Brosjö O, Smeland S, Lothe RA, Mertens F (2006) Identification of a novel amplicon at distal 17q containing the BIRC5/SURVIVIN gene in malignant peripheral nerve sheath tumours. J Pathol 209:492-500.

Taveggia C, Zanazzi G, Petrylak A, Yano H, Rosenbluth J, Einheber S, Xu X, Esper RM, Loeb JA, Shrager P, Chao MV, Falls DL, Role L, Salzer JL (2005) Neuregulin-1 type III determines the ensheathment fate of axons. Neuron 47:681-694.

van Heyningen P, Calver AR, Richardson WD (2001) Control of progenitor cell number by mitogen supply and demand. Curr Biol 11:232-241.

Vega JA, Rodríguez C, Medina M, del Valle ME (1990) Neuron specific enolase (NSE)-like and neurofilament protein (NFP)-like immunoreactivities in the rat dorsal root ganglia and sciatic nerve. Cell Mol Biol 36:537-546.

Wolpowitz D, Mason TB, Dietrich P, Mendelsohn M, Talmage DA, Role LW (2000) Cysteine-rich domain isoforms of the neuregulin-1 gene are required for maintenance of peripheral synapses. Neuron 25:79-91.

Zheng H, Chang L, Patel N, Yang J, Lowe L, Burns DK, Zhu Y (2008) Induction of abnormal proliferation by nonmyelinating schwann cells triggers neurofibroma formation. Cancer Cell 13:117-128.

Zhu Y, Ghosh P, Charnay P, Burns DK, Parada LF (2002) Neurofibromas in NF1: Schwann cell origin and role of tumor environment. Science 296: 920-922. 